\title{
Extraction and encapsulation of lesser galangal (Alpinia officinarum) essential oil using microwave pretreatment and spray drying
}

\author{
Tuan T. A. Nguyen $^{1}$, Dat T. Huynh ${ }^{1}, \&$ Natthakan Rungraeng ${ }^{2,3 *}$ \\ ${ }^{1}$ Faculty of Food Science and Technology, Nong Lam University, Ho Chi Minh City, Vietnam \\ ${ }^{2}$ School of Agro-Industry, Mae Fah Luang University, Chiang Rai, Thailand \\ ${ }^{3}$ Unit of Innovative Food Packaging and Biomaterials, Mae Fah Luang University, Chiang Rai, Thailand
}

ARTICLE INFO
Research Paper
Received: May 30, 2019
Revised: June 21, 2019
Accepted: June 28, 2019
Keywords
Alpinia officinarum
Essential oil
Encapsulation
Microwave pretreatment
Spray drying
*Corresponding author
Natthakan Rungraeng
Email: natthakan.run@mfu.ac.th

Cited as: Nguyen, T. T. A., Huynh, D. T., \& Rungraeng, N. (2019). Extraction and encapsulation of lesser galangal (Alpinia officinarum) essential oil using microwave pretreatment and spray drying.

The Journal of Agriculture and Development 18(3), 57-63.

\section{ABSTRACT}

Galangal (Alpinia officinarum) essential oil potentially exerts several health benefits such as antiproliferative, pain relief and fever reduction activities. The essential oil in this study was extracted using the microwave (MW) assisted treatment as an alternative method to conventional extraction. The samples were treated with $\mathrm{MW}$ at different power levels $(600,700$, and $800 \mathrm{~W})$ for 3 min before subjecting to a hydrodistillation extraction. The effect of sample:water ratio (1:1 and 1:0.5) was also investigated. The MW treatment at $600 \mathrm{~W}$ and sample:water ratio of 1:1 resulted in the highest amount of essential oil $(0.33 \%)$. The MW pretreatment had a positive effect on reducing the extraction time (from $3 \mathrm{~h}$ to $2.5 \mathrm{~h}$ ) observed at all MW power levels. The effect of essential oil loading capacity (10,20 and 30\%) on the encapsulation yield was evaluated. The in vitro antioxidative activity of the obtained powder was then measured. The highest encapsulation efficiency (86.5\%) was obtained from the $20 \%$ loading capacity, suggesting for a suitable amount of essential oil should be loaded for the encapsulation. The in vitro antioxidant activity of the encapsulated essential oil powders was determined. The $\mathrm{IC}_{50}$ of the powder was $2077 \mu \mathrm{g} / \mathrm{mL}$ using DPPH assay.

\section{Introduction}

Lesser galangal (Alpinia officinarum) belongs to the Zingiberaceae family, which is commonly used as a flavoring ingredient in South East Asian countries. The essential oil of this galangal is documented as rich in phenolic compounds (Tomazelli et al., 2018). Due to the high amount of phenolics, the essential oil from galangal has a number of health benefits such as antibacterial, antifungal, anticancer, antidiabetic, antiinflammatory, antioxidant (Chudiwal et al., 2010) and antiproliferative (Manosroi et al., 2006).

Hydrodistillation extraction of essential oil is known as the most commonly used method. How- ever, this method is time-consuming, low extraction efficiency and high energy consumption (Khumpirapang et al., 2018). Several innovative techniques of extracting the essential oil can be used to overcome the disadvantages of the conventional method (Danlami et al., 2014; Tongnuanchan \& Benjakul, 2014). Microwave pretreatment is a promising method to improve extraction efficiency and reducing the extraction time by losing the cell wall (Kittiphoom \& Sutasinee, 2015). By using this technique, the local overheating of the plant tissue can be avoided. Currently, using microwave pretreatment for extracting of essential oil, in particular for lesser galangal essential oil is very limited. Encapsulation of essen- 
tial oil using spray drying can be used to improve the application of the essential oil in the food industry. The resulted essential oil powder is suitable for heat-sensitive ingredients in foods and pharmaceuticals (Saénz et al., 2009). The aim of this study was to isolate essential oil from galangal using hydrodistillation with microwave pretreatment. The galangal essential oil was then encapsulated by spray drying to obtain an essential oil powder that is potential for industrial uses.

\section{Materials and Methods}

\subsection{Materials and chemicals}

The fresh Lesser galangal (A.officinarum) rhizomes were purchased from a local market, Chiang Rai, Thailand. The sample was selected by a firm texture, free from fungi or any damage by the pest.

In this research, microwave (Samsung ME711K) was used to pretreat the samples. A mixture of gum arabic and galangal essential oil was sprayed dried using a JCM Mini Lab SDE-10 spray dryer. In addition, the equipment used for analyzing essential oil and powdered essential oil included UV-Vis Spectrophotometer (Biochrom-Libra S22, UK), Microscope (Motic BA-310, Germany). The analytical grade chemicals DPPH (2, 2 - diphenyl -1-picryhydrazyl), methanol, hexane and ethanol) were purchased from local suppliers. The gum arabic was purchased from Chemipan Corporation Co., Ltd. All other chemicals and solvents used in this study were of analytical grade.

\subsection{Methods}

\subsubsection{Extraction of galangal essential oil}

One hundred grams of fresh galangal (A. officinarum) was mixed with water at ratio of $1: 1$ or 1:0.5, which was homogenized using a blender (Philips HR-2115). The mixture was then placed in a $500 \mathrm{~mL}$ round bottom flask. The flask was then covered by a plastic film with small holes and heated for $3 \mathrm{~min}$ with different power levels (600, 700 and $800 \mathrm{~W})$. The heated samples were subsequently inserted into a Clevenger apparatus for hydrodistillation extraction. The process was conducted for $2.5 \mathrm{~h}$ and continued until no more essential oil was obtained for comparison.

The essential oil was collected and transferred into amber colored vials, dehydrated with anhydrous sodium sulfate, and kept at $4^{0} \mathrm{C}$ in the dark until being analyzed.

The extraction yield of essential oil was calculated according to the equation given:

$\%$ Essential oil extraction yield $=$ weight of essential oil extracted $(\mathrm{g}) /$ weight of the sample $(\mathrm{g})$ $\times 100 \%$.

\subsubsection{Determined of DPPH free radical scav- enging activity}

The DPPH assay followed the protocol described by Sahoo et al. (2014) with some modifications. One milliliter of varying concentrations of the sample $(10,20,50$ and $100 \mu \mathrm{g} / \mathrm{mL})$ in methanol was mixed with $2 \mathrm{~mL}$ of $0.1 \mathrm{mM} \mathrm{DPPH}$ solution in methanol using a vortex mixer. Then the mixture was put in the dark at ambient temperature for $30 \mathrm{~min}$. The solution was measured at $517 \mathrm{~nm}$ using a UV/ visible spectrophotometer (Biochrom-Libra S22, UK). The inhibition percentage of DPPH in the extracts was calculated by using the following formula:

$$
\text { Inhibition }(100 \%)=\frac{A-B}{A} \times 100 \%
$$

where A control is the absorbance of the DPPH radical + methanol; $\mathrm{B}$ is the absorbance of DPPH radical + essential oil. The IC50 of the essential oil needed to inhibit $50 \%$ of the DPPH radicals obtained from the standard curve.

\subsubsection{Preparation of the coating material and oil loading}

Gum arabic was used as a wall material for the obtained essential oil. The method was conducted according to procedure of Fernandes et al. (2013). The gum arabic solution was prepared at $24 \%$ ( $\mathrm{w} / \mathrm{v}$, in water) in a $250 \mathrm{~mL}$ beaker. The solution were pre-mixed for $10 \mathrm{~min}$ by a magnetic stirrer. The solution was then allowed to cool to room temperature and kept in a shaking water bath at $25^{0} \mathrm{C}$ (90 rpm shaking rate) for one night to obtain a complete dissolved solution.

For different oil loading capacities, three ratios of essential oil to the wall material (i.e., $10 \%, 20 \%$ and $30 \%$ ) were calculated as follow:

Oil loading $\operatorname{capacity}(\%)=\frac{\text { Core }}{\text { Core }+ \text { Shell }} \times 100$ 
The mixtures was emulsified in shear homogenizer Ultra-Turrax T-25 (IKA, Werke GmbH \& Co. KG, Germany) for 5 min at 10,000 rpm until complete dispersion of the essential oil was obtained (Kausadikar et al., 2015). The prepared emulsions are shown in Table 1.

Table 1. The gum arabic and essential oil compositions in prepared emulsions

\begin{tabular}{lccc}
\hline Oil loading capacities & $10 \%$ & $20 \%$ & $30 \%$ \\
\hline Essential oil (core) & $6.7 \mathrm{~g}$ & $15 \mathrm{~g}$ & $25.8 \mathrm{~g}$ \\
Gum arabic (shell) & $60 \mathrm{~g}$ & $60 \mathrm{~g}$ & $60 \mathrm{~g}$ \\
\hline
\end{tabular}

\subsubsection{Spray drying}

The stable emulsions (about $250 \mathrm{~mL}$ ) were spray-dried using a JCM Mini Lab SDE-10 spray dryer (JCM best technology co., Ltd., Thailand). The dryer was equipped with a two-fluid nozzle atomizer ( $0.5 \mathrm{~mm}$ diameter). The operating conditions of the spray drying were inlet air temperature of $160^{\circ} \mathrm{C}$, outlet air temperature of $80^{\circ} \mathrm{C}$ and the feed flow rate was about $500 \mathrm{~mL} / \mathrm{h}$. The encapsulated powders were recovered from the collecting chamber. The powders were kept in a desiccator, then vacuum-sealed in high-density polyethylene (HDPE) plastic bags and stored at $-4^{0} \mathrm{C}$ until further analysis.

\subsubsection{Determination of encapsulation effi- ciency}

Encapsulation efficiency analysis was conducted to evaluate the ratio of surface oil to the entrapped oil in the capsule. The encapsulation efficiency was calculated using the following equation:

$\%$ Encapsulation Efficiency $=[$ total oil content (g)-surface oil content $(\mathrm{g})] /[$ total oil content $(\mathrm{g})$ surface oil content $(\mathrm{g})] \times 100$

Total oil content in the powder was determined as follow: a $500 \mathrm{~mL}$ flat-bottom flask was used to dissolve $5 \mathrm{~g}$ of a powder sample in $150 \mathrm{~mL}$ of distilled water and distilled for $1 \mathrm{~h}$ using Clevenger's apparatus. The essential oil was collected in amber bottles then oil content was obtained from weight measurement.

The method to determinate surface oil was described by Tomazelli et al. (2018). Twenty millilitre of hexane was added to $5 \mathrm{~g}$ of a powder and the mixture was stirred at $300 \mathrm{rpm}$ for $10 \mathrm{~min}$.
The suspension was filtered through a dried cellulose filter and was washed with $20 \mathrm{~mL}$ of hexane three times. The filter was kept in a desiccator under vacuum to vaporize all residual solvent until obtaining constant weight.

\subsubsection{Solubility and moisture content}

For solubility (Márquez-Gómez et al., 2018), 10 $\mathrm{g}$ of a sample was dissolved in $25 \mathrm{~mL}$ of solvent (distilled water, vegetable oil and ethanol (95\% $\mathrm{v} / \mathrm{v})$ ), and they were maintained under constant stirring for $5 \mathrm{~min}$ at ambient temperature. Then the suspension was observed for the solubility or microcapsule cluster.

The moisture content (MC) of essential oil powder was determined using a thermogravimetric analysis. The sample $(2 \mathrm{~g})$ was loaded into the aluminum cups and heated at $105^{\circ} \mathrm{C}$ in a hot air oven until a constant weight was obtained.

$$
\mathrm{MC}_{\mathrm{wb}}=\frac{\mathrm{W}_{\mathrm{f}}-\mathrm{W}_{\mathrm{i}}}{\mathrm{W}_{\mathrm{i}}}
$$

where: $\mathrm{W}_{\mathrm{i}}$ is the initial weight of sample; $\mathrm{W}_{\mathrm{f}}$ is the final weight of the sample.

\subsubsection{Scanning electron microscopy (SEM) of essential oil powders}

Scanning electron microscope (SEM) was operated at $10 \mathrm{kV}$ (LEO/1450 VP) for investigating the microstructure of essential oil powders. Before analysis, samples were sputtered with gold in an anion-sputtering apparatus (Leica EM SCD500, Leica Microsystems, Germany).

\subsubsection{Statistical analysis}

The results were analyzed by analysis of variance (ANOVA) $(P<0.05)$. When a significant difference was found between the samples, Duncan's Multiple Comparison Test was applied $(P$ $<0.05$ ) by using SPSS software (IBM Corp. Released 2015. IBM SPSS Statistics for Windows, Version 23.0. Armonk, NY: IBM Corp). All tests were carried out in duplicate.

\section{Results and Discussion}

\subsection{Extraction essential oil yield}

Microwave pretreatment is assumed to be effective for essential oil extraction from galangal rhi- 
Table 2. The essential oil yield (\%) and the extraction time $e^{1,2}$

\begin{tabular}{lccc}
\hline & $\begin{array}{c}\text { Microwave power and } \\
\text { sample: water ratio }\end{array}$ & $\begin{array}{c}\text { Essential oil } \\
\text { extraction yield } \\
(\%)\end{array}$ & $\begin{array}{c}\text { Extraction time by } \\
\text { hydrodistillation } \\
(\mathrm{h})\end{array}$ \\
\hline & $600 \mathrm{~W}(1: 1)$ & $0.33 \pm 0.01^{\mathrm{a}}$ & 2.5 \\
Microwave pretreatment & $700 \mathrm{~W}(1: 1)$ & $0.21 \pm 0.01^{\mathrm{c}}$ & 2.5 \\
for 3 min & $800 \mathrm{~W}(1: 1)$ & $0.20 \pm 0.01^{\mathrm{c}}$ & 2.5 \\
& $600 \mathrm{~W}(1: 0.5)$ & $0.27 \pm 0.01^{\mathrm{b}}$ & 2.5 \\
Non-microwave pretreatment & $700 \mathrm{~W}(1: 0.5)$ & $0.21 \pm 0.01^{\mathrm{c}}$ & 2.5 \\
${ }^{1}$ Value are means + standard & Control & $0.22 \pm 0.02^{\mathrm{c}}$ & 2.5 \\
\hline
\end{tabular}

${ }^{1}$ Value are means \pm standard deviation.

${ }^{2}$ Value with the same columns followed by different letter are significantly different $(P<0.05)$, based on Duncan multiple using SPSS, version 23.

zome. In this experiment, the pretreatment was applied at different power levels and the results are shown in Table 2.

The MW pretreatment effectively reduced the extraction time by $30 \mathrm{~min}$ (from $3.0 \mathrm{~h}$ to $2.5 \mathrm{~h}$ ) while the essential oil yield was insignificant different from that of the untreated sample $(P<$ 0.05). The MP may affect the cell wall of the galangal resulting in faster release of essential oil during extraction. Microwave power may provide energy to the cells of the sample so that it can quickly increase in heat and force and loosen the plant matrix cells wall (Proestos \& Komaitis, 2008; McMillan et al., 2013). The microscopy imaging of MW pretreated samples was illustrated in Figure 1. The MW pretreatment somehow showed its effects on the cell walls as cracking (red arrows, on the right), suggesting for its role of assistance in essential oil extraction. Thus, the treatment at $600 \mathrm{~W}$ resulted in the highest oil yield $(P<0.05)$. The higher power levels $(700 \mathrm{~W}$ and $800 \mathrm{~W})$ of microwave radiation may lead to losing the volatile compounds during extraction. In MW pretreatment, the lower extraction yield found in high microwave power may be due to high evaporation of volatile compounds (Behera et al., 2004).

The sample:water ratio of 1:1 increased the essential oil yield observed at $600 \mathrm{~W}$ treatment (from $0.27 \%$ to $0.33 \%, P<0.05$ ). The water content of plant tissue affects the penetration of microwave (Jack \& Cooper, 2005), and cause intensive thermal effects. The sample:water ratio of 1:1 may give adequate moisture for the penetration of MW, resulting in the higher yield as observed.

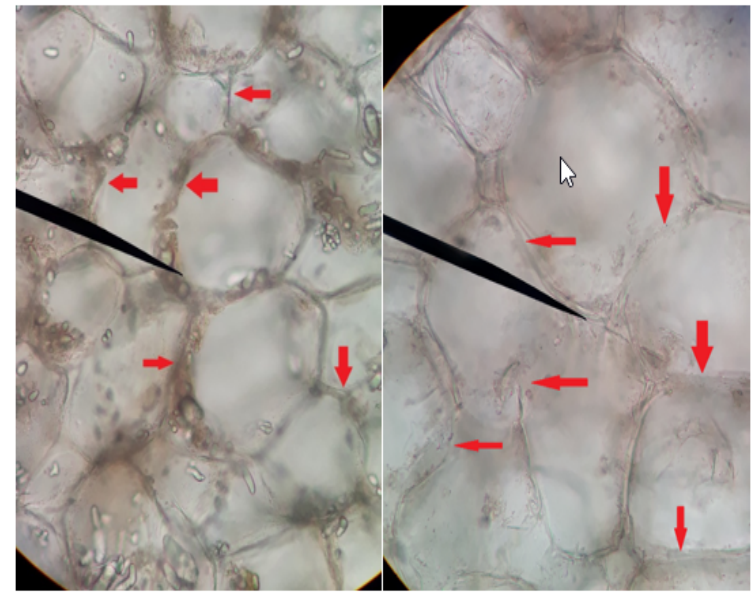

Figure 1. The sample before (left) and after (right) microwave pretreatment, the red arrows show the junctions between galangal rhizome cells.

\subsection{Microencapsulation lesser galangal ( $A$. of- ficinarum) essential oil by spray drying}

The ultimate purpose of the encapsulation of the essential oil is to preserve essential oil quality as well as increase the application in the food industry. In this study, the spray drying method was used to encapsulate the obtained galangal essential oil. The important quality parameter in the encapsulation of oils by spray drying is encapsulation efficiency value (Bae \& Lee, 2008). The values of encapsulation efficiency are summarized in Table 3.

For the spray drying encapsulation, the essential oil loading capacity potentially affects the encapsulation efficiency (Ahn et al., 2008; Frascareli et al., 2012). In this study, $20 \%$ of essential oil loading capacity gave the highest EE (86.5\%). 
Table 3. Effect of the oil loading capacity of powder encapsulation of $A$. officinarum essential oil ${ }^{1,2}$

\begin{tabular}{ccccc}
\hline $\begin{array}{c}\text { Oil loading } \\
\text { capacity }(\%)\end{array}$ & $\begin{array}{c}\text { Surface oil content } \\
(\mathrm{g} / 100 \mathrm{~g})\end{array}$ & $\begin{array}{c}\text { Total oil content } \\
(\mathrm{g} / 100 \mathrm{~g})\end{array}$ & $\begin{array}{c}\text { Encapsulation } \\
\text { efficiency }(\%)\end{array}$ & $\begin{array}{c}\text { Moisture content } \\
(\%)\end{array}$ \\
\hline $10 \%$ & $3.75 \pm 0.35^{\mathrm{a}}$ & $8.6 \pm 0.2^{\mathrm{a}}$ & $56.6 \pm 5.1^{\mathrm{b}}$ & $5.61 \pm 0.83^{\mathrm{a}}$ \\
$20 \%$ & $1.23 \pm 0.35^{\mathrm{b}}$ & $9.5 \pm 0.7^{\mathrm{a}}$ & $86.5 \pm 5.0^{\mathrm{a}}$ & $4.85 \pm 0.64^{\mathrm{a}}$ \\
$30 \%$ & $3.20 \pm 0.35^{\mathrm{a}}$ & $9.2 \pm 1.1^{\mathrm{a}}$ & $64.6 \pm 0.6^{\mathrm{b}}$ & $6.15 \pm 0.78^{\mathrm{a}}$ \\
\hline
\end{tabular}

\footnotetext{
${ }^{1}$ Value means \pm standard deviation.

${ }^{2}$ Value with the same columns followed by a different letter (a to c) are significantly different $(P<0.05)$, based on Duncan multiple.
}

Surface oil retention is another parameter that can be used to evaluate the process of encapsulation. The presence of surface oil content relates to the physical properties of spray-dried powders because it can lead to rapid lipid oxidation (Fäldt \& Bergenståhl, 1995; Jimenez et al., 2004). Surface oil content was found lowest in $20 \%$ loading capacity level $(1.23 \%)$. The surface oil retention was inversely correlated to the encapsulation efficiency (as seen in Table 3). Thus, the higher core material inversely proportionates to the surface oil retention. Interestingly, at $30 \%$ oil loading capacity, the surface oil retention was also found to be higher than in the $20 \%$ oil loaded sample. This phenomenon can be explained by the wall material:essential oil ratio. At $30 \%$ oil loading capacity, the wall material was not adequate to entrap the entire amount of essential oil and consequently resulted in higher surface oil content. Since the high encapsulation efficiency and the low surface oil contents are preferred targets for a promising encapsulation, oil loading capacity at $20 \%$ was the most suitable level for essential oil encapsulation by spray drying. There were reported that a ratio of 1:4 (core to wall ratio) provided the most suitable stable to varying volatile cores (Saénz et al., 2009; Fernandes et al., 2013; Kha et al., 2014).

\subsection{The moisture content and solubility}

The moisture content of the dried powders obtained at difference oil loading capacities was evaluated (Table 3). There was insignificant interaction between the oil loading capacity and the final moisture content $(P>0.05)$. The moisture content is an important parameter for powdered products since oxidative reactions of the oil tend to increase at increasing moisture content. The moisture content of the essential powder under control conditions was less than $7 \%$, which is in range of most dried powders used in the food industry (Kha et al., 2014).

\subsection{The antioxidative activity of essential oil powder}

In this part, the DPPH assay was used to investigate the antioxidative activity of the essential oil powder and the data is shown in Table 4 . It can be seen that the antioxidative activity of the encapsulated powders was significantly lower than that of freshly extracted essential oil $(P<$ $0.05)$. This was observed in all level of oil loading capacities. After spray drying, the $\mathrm{IC}_{50}$ of the essential oil extracted from the powders increased 2 -fold (Table 4). This means that the antioxidative activity of the extracted essential oil from the encapsulated powder significantly reduced. The negative effect of encapsulation by spray drying on the antioxidative activity of essential oil may be attributed to the thermal degradation of antioxidants during exposure to high temperature (Couto et al., 2012; Fernandes et al., 2014).

Table 4. The $\mathrm{IC}_{50}$ of galangal essential oil extracted from encapsulated powders and before encapsulation determined by DPPH assay ${ }^{1,2}$

\begin{tabular}{cc}
\hline The per cent oil loading & $\begin{array}{c}\text { The IC } 50 \text { value } \\
(\mu \mathrm{g} / \mathrm{mL})\end{array}$ \\
\hline $10 \%$ & $2123 \pm 138^{\mathrm{a}}$ \\
$20 \%$ & $2077 \pm 135^{\mathrm{a}}$ \\
$30 \%$ & $1934 \pm 249^{\mathrm{a}}$ \\
$\begin{array}{c}\text { Essential oil before } \\
\text { encapsulation }\end{array}$ & $1039 \pm 66^{\mathrm{b}}$ \\
\hline
\end{tabular}

${ }^{1}$ Mean \pm standard deviation.

${ }^{2}$ Value with the same columns followed by a different letter (a to c) are significantly different $(P<0.05)$, based on Duncan multiple.

\subsection{SEM microstructure}

The scanning electron microscopy (SEM) was used to study the morphologies of the encapsulated essential oil powder. In all samples, the particle size of the powders ranged from 5 to $30 \mu \mathrm{m}$ (estimated under SEM micrographs, Figure 2). 
The shrinkage of the surface was observed in these particles. According to Kha et al. (2014), during drying and cooling, the surface depressions likely result in the shrinkage. The outer surface showed a smooth wall without significant fissures or cracks. The closed structure of the particles can significantly reduce oxygen exposure and thus prevent the oxidation of the core material (essential oil).
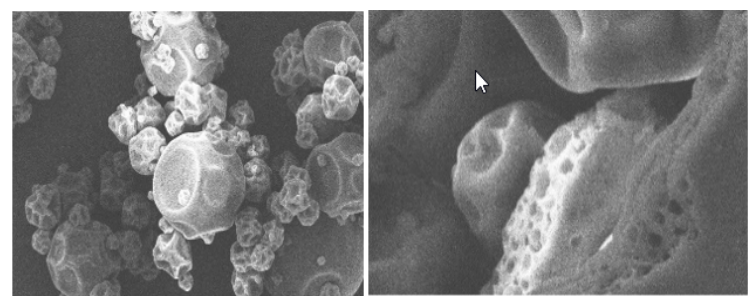

Figure 2. The SEM micrograph of the surface (left) and internal (right) microstructures of the encapsulation powders, the imaging observed at a magnification levels of 1000X and 5000X, respectively.

The cross-sectional SEM images revealed the internal structure of the particles. Homogenous spherical holes were observed indicating an even distribution of the essential oils in gum arabic. The similar results were also documented in the study of Kha et al., (2014). These results again led to a high level of encapsulation effectiveness.

\subsection{The solubility of powder in different sol- vents}

The solubility of the powder is an indicator for selecting a suitable medium to dissolve the powder and thus clarify industrial application. The powders obtained by spray drying were completely dissolved in vegetable oil. In distilled water, the gum arabic was mostly dissolved but the essential oil formed a consistent colloid (Figure $3)$. Such solubility results of the powder were considered to be applicable for most food matrices (Márquez - Gomez et al., 2018).

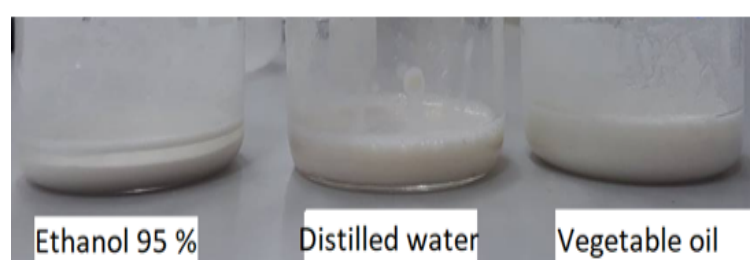

Figure 3. The solubility of powder in different solvents.

\section{Conclusions}

The processes of isolating the essential oil from lesser galangal using microwave pretreatment and encapsulation of the essential oil were studied. The highest oil essential extraction $(0.33 \%)$ was achieved using $600 \mathrm{~W}$ microwave power treatment with the sample:water ratio of 1:1. Using the MW pretreatment can reduce the extraction time by $30 \mathrm{~min}$. Excessive microwave radiation power could negatively affect the extracted oil yield. The most suitable encapsulation condition for encapsulating galangal essential oil with gum arabic was $20 \%$ loading capacity. At $20 \%$ loading capacity, the essential oil powder showed a comparative in vitro antioxidative activity with other treatments. The developed product can be further used as an flavoring agent in food and beverage industries.

\section{Acknowledgements}

The authors would like to thank The ASEAN International Mobility for Students Programme (AIMS) and Advanced Programme in Food Technology for facilitating collaboration between Mae Fah Luang University and Nong Lam University Ho Chi Minh City.

\section{References}

Ahn, J. H., Kim, Y. P., Lee, Y.M., Seo, E. M., Lee, K. W., \& Kim, H. S. (2008). Optimization of microencapsulation of seed oil by response surface methodology. Food Chemistry 107(1), 98-105.

Bae, E., \& Lee, S. (2008). Microencapsulation of avocado oil by spray drying using whey protein and maltodextrin. Journal of Microencapsulation 25(8), 549-560.

Behera, S., Nagarajan, S., \& Rao, L. J. M. (2004). Microwave heating and conventional roasting of cumin seeds (Cuminum cyminum L.) and effect on chemical composition of volatiles. Food Chemistry 87(1), 25-29.

Chudiwal, A., Jain, D., \& Somani, R. (2010). Alpinia galanga Willd.-An overview on phyto-pharmacological properties. Indian Journal of Natural Products and Resources 1(2), 143-149.

Couto, R. O., Conceição, E. C., Chaul, L. T., Oliveira, E. M., Martins, F. S., Bara, M. T. F., Rezende, K. R., Alves, S. F., \& Paula, J. R. (2012). Spray-dried rosemary extracts: physicochemical and antioxidant properties. Food Chemistry 131(1), 99-105.

Danlami, J. M., Arsad, A., Zaini, M. A. A., \& Sulaiman, H. (2014). A comparative study of various oil extraction techniques from plants. Reviews in Chemical Engineering 30(6), 605-626. 
Fäldt, P., \& Bergenståhl, B. (1995). Fat encapsulation in spray-dried food powders. Journal of the American Oil Chemists' Society 72(2), 171-176.

Fernandes, R. V. d. B., Borges, S. V., \& Botrel, D. A. (2013). Influence of spray drying operating conditions on microencapsulated rosemary essential oil properties. Food Science and Technology 33, 171-178.

Fernandes, R. V. d. B., Marques, G. R., Borges, S. V., \& Botrel, D. A. (2014). Effect of solids content and oil load on the microencapsulation process of rosemary essential oil. Industrial Crops and Products 58, 173181.

Frascareli, E., Silva, V., Tonon, R., \& Hubinger, M. (2012). Effect of process conditions on the microencapsulation of coffee oil by spray drying. Food and Bioproducts Processing 90(3), 413-424.

Jack, S. A., \& Cooper, K. (2005). Microwave endometrial ablation: An overview. Reviews in Gynaecological Practice 5(1), 32-38.

Jimenez, M., Garcia, H., \& Beristain, C. (2004). Spraydrying microencapsulation and oxidative stability of conjugated linoleic acid. European Food Research and Technology 219(6), 588-592.

Kausadikar, S., Gadhave, A. D., \& Waghmare, J. (2015). Microencapsulation of lemon oil by spray drying and its application in flavour tea. Advanced Applied Science Research 6(4), 69-78.

Kha, T. C., Nguyen, M. H., Roach, P. D., \& Stathopoulos, C. E. (2014). Microencapsulation of gac oil by spray drying: optimization of wall material concentration and oil load using response surface methodology. Drying Technology 32(4), 385-397.

Khumpirapang, N., Pikulkaew, S., Anuchapreeda, S., \& Okonogi, S. (2018). Alpinia galanga oil-A new natural source of fish anaesthetic. Aquaculture Research 49(4), 1546-1556.

Kittiphoom, S., \& Sutasinee, S. (2015). Effect of microwaves pretreatments on extraction yield and quality of mango seed kernel oil. International Food Research Journal, 22(3), 960-964.
Manosroi, J., Dhumtanom, P., \& Manosroi, A. (2006). Anti-proliferative activity of essential oil extracted from Thai medicinal plants on KB and P388 cell lines. Cancer Letters 235(1), 114-120.

Márquez-Gómez, M., Galicia-García, T., MárquezMeléndez, R., Ruiz-Gutiérrez, M., \& Quintero-Ramos, A. (2018). Spray-dried microencapsulation of orange essential oil using modified rice starch as wall material. Journal of Food Processing and Preservation 42(2), e13428.

McMillan, J. R., Watson, I. A., Ali, M., \& Jaafar, W. (2013). Evaluation and comparison of algal cell disruption methods: microwave, waterbath, blender, ultrasonic and laser treatment. Applied Energy 103, 128134.

Proestos, C., \& Komaitis, M. (2008). Application of microwave-assisted extraction to the fast extraction of plant phenolic compounds. LWT-Food Science and Technology 41(4), 652-659.

Saénz, C., Tapia, S., Chávez, J., \& Robert, P. (2009). Microencapsulation by spray drying of bioactive compounds from cactus pear (Opuntia ficus-indica). Food Chemistry 114(2), 616-622.

Sahoo, S., Parida, R., Singh, S., Padhy, R. N., \& Nayak, S. (2014). Evaluation of yield, quality and antioxidant activity of essential oil of in vitro propagated Kaempferia galanga Linn. Journal of Acute Disease 3(2), 124-130.

Tomazelli, J. O., Kuhn, F., Padilha, P., Vicente, L., Costa, S., Boligon, A., Scapinello, J., Nesi, C., Dal Magro, J., \& Castellví, S. L. (2018). Microencapsulation of essential thyme oil by spray drying and its antimicrobial evaluation against Vibrio alginolyticus and Vibrio parahaemolyticus. Brazilian Journal of Biology 78(2), 311-317.

Tongnuanchan, P., \& Benjakul, S. (2014). Essential oils: extraction, bioactivities, and their uses for food preservation. Journal of Food Science 79(7), R1231-R1249. 